\title{
Best practice VII Enabling the private sector to manage its impact on the SDGs
}

\author{
Charlotte Portier
}

The 17 sustainable development goals (SDGs) are anticipated to generate over US\$12 trillion worth of business opportunities by 2030, which makes thousands of small and large companies around the world well incentivized to work towards achieving the goals. But until now, the lack of a uniform methodology for business to measure and report on their contributions to the global goals had become a stumbling block. Developed by Global Reporting Initiative (GRI) and the United Nations Global Compact with support from Shift and $\mathrm{PwC}$ - and as part of the Action Platform on Reporting on the SDGs - the publication, Integrating the SDGs into Corporate Reporting: A Practical Guide ${ }^{1}$ completes a toolkit that aims to boost and improve businesses' reporting on the global goals and their efforts to achieve the 2030 agenda.

This new practical guide helps companies of all sizes to prioritize SDG targets to act and report on, set related business objectives and measure and report on progress.

The newly published guide specifically addresses the current challenges in the reporting arena, namely the need for harmonization and the prioritization process. As such it does not create a new reporting framework but builds on the Ten Principles of the UN Global Compact, the UN Guiding Principles on Business and Human Rights, and the GRI Sustainability Reporting Standards. It discourages businesses from selecting SDGs and related targets based on what is easiest for them to report on. Rather, companies should focus on what accounts for the highest priorities and, therefore, is material for their business. The report calls for companies to report on both their positive and negative impacts on the SDGs.

The publication is meant to be used together with other relevant tools released by GRI, the UN Global Compact and their partners as part of a company's regular reporting cycle, such as Business Reporting on the SDGs: An Analysis of the Goals and Targets ${ }^{2}$, which lists qualitative and quantitative disclosures for SDG targets that are likely to be relevant to businesses regardless of size, sector or operating location. It also lists illustrative actions that businesses can take to contribute to the achievement of the targets. 


\section{Aims and goals}

GRI's aim is to enable business to disclose SDG-related information and manage their impact on sustainable development. Business can measure their contribution to the global goals to take informed decisions and maximize their positive contributions.

\section{Benefit for organizations}

By empowering business to report on their impact on sustainable development and the SDGs, GRI realizes its mission: to empower decisions that create social, environmental and economic benefits for everyone.

\section{Notes}

1 GRI and UN Global Compact (2018). Integrating the SDGs into Corporate Reporting: A Practical Guide. Retrieved from: https://www. globalreporting.org/public-policy-partnerships/sustainable-development/ integrating-sdgs-into-sustainability-reporting/.

2 GRI and UN Global Compact (2017). Business Reporting on the SDGs: An Analysis of the Goals and Targets. Retrieved from: https://www. globalreporting.org/public-policy-partnerships/sustainable-development/ integrating-sdgs-into-sustainability-reporting/. 